\title{
Multi-drug resistance and extended spectrum beta lactamase producing Gram negative bacteria from chicken meat in Bharatpur Metropolitan, Nepal
}

\author{
Anil Shrestha ${ }^{1}$, Anup Muni Bajracharya ${ }^{1}$, Hemraj Subedi ${ }^{1}$, Raju Shah Turha ${ }^{1}$, Sachin Kafle ${ }^{1}$, Saroj Sharma ${ }^{1}$,
} Sunil Neupane ${ }^{1}$ and Dhiraj Kumar Chaudhary ${ }^{2^{*}}$

\begin{abstract}
Objective: Multidrug resistance (MDR) and extended spectrum beta lactamase (ESBL) producer Gram negative bacteria are considered as a major health problem, globally. ESBL enzyme hydrolyses the beta lactam ring of third generation cephalosporins, which alters the structure of the antibiotic. Due to the modification in structure of the antibiotic, bacteria show resistance to these antibiotics. Resistant bacterial strains are transmitted to humans from animals through consumption of uncooked meat, through contact with uncooked meat and meat surfaces. This study aims to assess bacteriological profile and analyze the situation of antibiotic resistance, multidrug resistance, and ESBL producing Gram negative bacteria in chicken meat.

Results: A total of 38 chicken meat samples were studied in which $103 \mathrm{Gram}$ negative bacteria were isolated. Species of Gram negative bacteria were identified as Citrobacter spp. (44.7\%), Salmonella spp. (26.2\%), Proteus spp. (18.4\%), Escherichia coli (4.8\%), Shigella spp. (3.9\%), Pseudomonas spp. (1.9\%), and Klebsiella spp. (1.0\%). The prevalence of MDR isolates was found to be $79.6 \%$. Total ESBL producer was 36.9\% and ESBL producer among MDR was 34.9\%. This concludes wide range of antibiotic resistance bacteria is prevalent in raw chicken meat.
\end{abstract}

Keywords: Gram negative bacteria, Extended spectrum beta lactamase, Multidrug resistance, Chicken meat, Antibiotics

\section{Introduction}

Multidrug resistance (MDR) is the ability of bacteria to resist different classes of antibiotics (three or more than three classes of antibiotics) which are structurally different and have different molecular targets [1]. Antibiotic resistance is a result of antibiotic use. The greater the volume of antibiotics used, the greater will be the chances of arising antibiotic resistance population of bacteria [2]. There is growing evidence which revealed antibiotic resistance has been promoted by widespread use of non-therapeutic antibiotics in animals [3]. The misuse of

\footnotetext{
*Correspondence: dhirajchaudhary2042@gmail.com

2 Department of Microbiology, Prithu Technical College, Institute of Agriculture and Animal Science, Tribhuvan University, Dang, Nepal Full list of author information is available at the end of the article
}

antibiotic can lead to the development of bacterial resistance towards antibiotic, increases the burden of chronic disease, and increases costs of health services. Resistant bacteria are transmitted to human through direct contact with animal, by exposure to animal manure, through consumption of uncooked meat, and through contact with meat surfaces [4].

The prevalence of MDR isolates and ESBL producing isolates is increasing in humans as well as animal. Fecal carriage of ESBL gene has been identified as the major reservoir in the environment. Bacterial species that carry ESBL genes are normal inhabitants of gastrointestinal tract, and food is a potential source of them [5]. Meat harbor different bacteria as an inherent contamination and are further contaminated during handling, improper 
dressing, cleaning, insanitary condition, and unhygienic practices of selling meat. Consumption of these unsafe meat arise public health hazards $[6,7]$. This study aims to find the prevalence of MDR and ESBL producing isolates from chicken meat in Bharatpur metropolitan.

\section{Main text}

This cross-sectional study was conducted in Microbiology Laboratory of Balkumari College, Tribhuvan University, Bharatpur, Nepal from 2016 December to 2017 June. Random sampling was done to collect non-repeated single meat sample from different slaughter house located in different places of Bharatpur, Nepal. Sample size was determined based on prevalence rate as reported by previous study [8]. A total of 38 samples of chicken meat were included in this study.

\section{Methodology}

The chicken meat samples (15 g; each $5 \mathrm{~g}$ from thighs, breasts, and wings of same chicken) prior to refrigeration were aseptically collected in a sterile beaker. The beaker was properly capped with aluminum foil and transported quickly to the laboratory. Samples were transferred to conical flask containing peptone water and incubated for $30 \mathrm{~min}$ at $80 \mathrm{rpm}$ at room temperature in a rotator (Thermo Scientific Compact Digital Mini Rotator; Cat. No. 8880025). After incubation, $1 \mathrm{ml}$ of contaminated peptone water (HiMedia, M028) was further transferred to two different test tubes containing nutrient broth (HiMedia, MM244) and Selenite F broth (Himedia, M025S). Test tubes were incubated aerobically at $37{ }^{\circ} \mathrm{C}$ overnight. After incubation, samples from nutrient broth were streaked in m-endo agar (HiMedia, M1106) and MacConkey agar plates (HiMedia, M081). Samples from Selenite F broth were streaked to Salmonella-Shigella agar plates (HiMedia, M108). All the plates were incubated aerobically at $37^{\circ} \mathrm{C}$ for $24 \mathrm{~h}$. Gram negative isolates were identified by following standard microbiological techniques which include studies of colony morphology, staining reactions and various biochemical properties [9]. Pure isolates were identified by performing the standard biochemical tests (SIM test, MRVP test, citrate test, urease test) [8].

Antibiotic susceptibility test of isolates was performed following modified Kirby-bauer disk diffusion method as recommended by Clinical and Laboratory Standards Institute (CLSI) [10]. The antibiotics used in this study were nitrofurantoin (NIT), ampicillin (Amp), cefotaxime (CTX), ceftazidime (CAZ), gentamicin (Gen), ciprofloxacin (Cip), colisitin $(\mathrm{Cl})$, doxycycline hydrochloride (DO), imipenam (Imp) and polymyxin B (Pb). Screening of ESBL was performed by using ceftazidime $(30 \mu \mathrm{g})$ and cefotaxime $(30 \mu \mathrm{g})$ disks. The zone of inhibition
(ZOI) $\leq 22 \mathrm{~mm}$ for ceftazidime and $27 \mathrm{~mm}$ for cefotaxime was considered as potential ESBL producer as recommended by CLSI. For the conformation of ESBL, combination disk method was used. The combination of ceftazidime and cefotaxime alone and in combination with clavulanic acid (CA) $(10 \mu \mathrm{g})$ were used. An increase ZOI of $\geq 5 \mathrm{~mm}$ for either antimicrobial agent tested in combination with $C A$ versus its zone when tested alone confirms ESBL positive. All the antibiotic discs used in this study were purchased from Himedia, India. For biochemical tests and antibiotics susceptibility tests, following reference strains were used as quality control strains: E coli ATCC 25922; Pseudomonas aeruginosa ATCC 27853; Klebsiella pneumonia ATCC 700603; Proteus mirabilis ATCC 35659; and Salmonella typhimurium ATCC 14028.

All data were entered in Microsoft Excel and Chi square test was performed. $P$ value was calculated and considered significant only when it was less than 0.05 .

\section{Results}

Based on sanitation parameters (hygienic condition of slaughter house, chopping boards, and showcased meat, and cleanliness of slaughter personnel), we have categorized meat samples as good sanitation and poor sanitation type. Out of 38 collected samples, 14 samples were grouped into good sanitation type and 24 samples were grouped into poor sanitation type (Additional file 1: Table S1). A total of 103 Gram negative bacterial strains were isolated among which only one sample showed growth with single isolate and remaining all samples showed growth with multiple isolates. Out of 103 bacterial isolates, $27(26.2 \%)$ and $76(73.8 \%)$ bacterial isolates were obtained from good sanitation and poor sanitation type meat samples, respectively (Additional file 1: Table S2). Among 103 Gram negative isolates, the number of Citrobacter spp., Salmonella spp., Proteus spp., Escherichia coli, Klebsiella spp., Shigella spp. and Pseudomonas spp. were 46 (44.7\%), 26 (26.2\%), 19 (18.4\%), 5 (4.8\%), 1 (1.0\%), 4 (3.9\%) and 2 (1.9\%), respectively (Fig. 1).

Among 103 Gram negative isolates, 36 (34.9\%) of bacteria were MDR producing extended spectrum beta lactamase, in which $13(12.6 \%)$ strains of Salmonella spp. account to be highest MDR ESBL producer (Table 1). From both good sanitation and poor sanitation type meat samples, $82(79.6 \%)$ isolates were detected as multidrug resistance. Among MDR isolates, Salmonella spp. (85.2\%) and Pseudomonas spp. (100.0\%) showed high prevalent of MDR. The frequency of ESBL producer bacteria in meat samples was found to be 38 (36.9\%). Pseudomonas spp. (100.0\%), E. coli spp. (40.0\%), and Salmonella spp. (55.2\%) showed high prevalent of ESBL producer bacteria (Table 2). Statistical analysis showed that there was no 


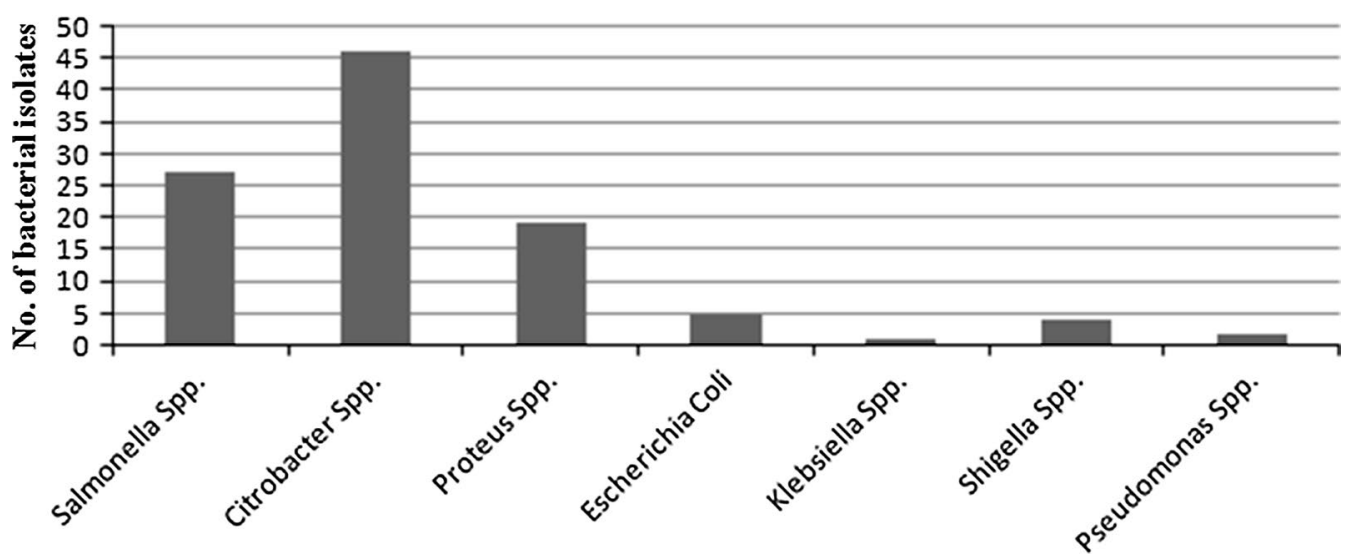

Fig. 1 Distribution of bacterial isolates in chicken meat samples

Table 1 Frequency of multi-drug resistance ESBL producing bacteria

\begin{tabular}{lc}
\hline Bacteria & $\begin{array}{l}\text { Multidrug resistance bacteria } \\
\text { producing ESBL (\%) }\end{array}$ \\
\hline Citrobacter spp. & $11(10.7)$ \\
Salmonella spp. & $13(12.6)$ \\
Proteus spp. & $5(4.9)$ \\
E. coli & $2(1.9)$ \\
Shigella spp. & $3(2.9)$ \\
Pseudomonas spp. & $2(1.9)$ \\
Total & $36(34.9)$ \\
\hline
\end{tabular}

Table 2 Frequency of MDR and ESBL producing bacteria

\begin{tabular}{llc}
\hline Bacteria & $\begin{array}{l}\text { Multi-drug resistance } \\
\text { bacteria (\%) }\end{array}$ & $\begin{array}{l}\text { ESBL producer } \\
\text { bacteria (\%) }\end{array}$ \\
\hline Citrobacter spp. $(\mathrm{n}=46)$ & $36(78.3)$ & $12(26.1)$ \\
Salmonella spp. $(\mathrm{n}=27)$ & $23(85.2)$ & $15(55.2)$ \\
Proteus spp. $(\mathrm{n}=19)$ & $14(73.7)$ & $5(26.3)$ \\
E. coli $(\mathrm{n}=5)$ & $4(80.0)$ & $2(40.0)$ \\
Shigella spp. $(\mathrm{n}=4)$ & $3(75.0)$ & $2(40.0)$ \\
Pseudomonas spp. $(\mathrm{n}=2)$ & $2(100.0)$ & $2(100.0)$ \\
Total & $82(79.6)$ & $38(36.9)$ \\
\hline
\end{tabular}

significant association in prevalence of MDR and ESBL producer isolates with sanitation condition of meat samples $(P>0.05)$.

The antibiotic resistance pattern of the Citrobacter spp. showed highest $32.6 \%$ isolates were resistant to the imipenam followed by cefotaxime and ciprofloxacin (19.5\%, each). All the strains of Salmonella spp. were resistant to ampicillin (100\%) followed by nitofurantoin (84.6\%) and doxycycline hydrochloride (84.0\%). Proteus spp. revealed $29.4 \%$ resistivity to imipenam followed by ciprofloxacin
(11.7\%) (Additional file 1: Table S3). The antibiotic resistivity pattern of $E$. coli showed all the isolates were resistant to ampicilin followed by colistin and polymyxin $\mathrm{B}$ (80\%, each), whereas resistivity were not detected to doxycycline hydrochloride, gentamicin and imipenam.

\section{Discussion}

Animals and its products are potent source of MDR bacteria. Consumption of unhealthy meat, unhygienic livestock practices and polluted environment surrounding slaughter house contribute for transmission of several diseases and antibiotic resistant bacterial strains $[4,11]$. In Nepal, information regarding prevalence of MDR and ESBL producer Gram negative bacteria in chicken meat is poorly available. Therefore, this study was conducted to assess prevalence of MDR and ESBL producer Gram negative bacteria in chicken meat.

This study observed that Citrobacter spp., Salmonella spp., Proteus spp., E. coli, Klebsiella spp., Shigella spp. and Pseudomonas spp. were the major Gram negative bacteria among 103 bacterial isolates (Fig. 1). Most of these isolates are considered as pathogenic which suggest chicken meat is an important source of food borne infection. Similar pattern of Gram negative bacteria were found in several other studies conducted in North East India, China, South Korea, Vietnam, and Spain [11-15].

Citrobacter species are frequently found in water, soil, food, and the intestines of animals and humans. Most human cases of Citrobacter infection are caused by Citrobacter freundii and Citrobacter koseri [16, 17]. The prevalence of MDR and ESBL producing Citrobacter spp. was found to be $78.3 \%$ and $26.1 \%$, respectively. These magnitudes are comparable with the study conducted by Kanamori et al. which reported 19.3\% of Citrobacter spp. was ESBL producer [18]. Citrobacter spp. is a low virulence bacterium and thus can persist in host population 
for long periods. Over time, they accumulate resistance determinants which may transform to more virulent organisms [17].

The prevalence of Salmonella spp. was $26.2 \%$ which is similar to the studies carried out in USA and South Korea [13, 19]. In contrast, higher prevalence rate of Salmonella spp. was found in Southern Thailand (67.5\%) [20] and China (54.0\%) [12]. Prevalence of Salmonella spp. in chicken meat indicates that contamination may occur during slaughtering process or evisceration. Salmonella spp. in chicken meat can be considered as important cause of food borne Salmonellosis [13, 21]. Salmonella spp. isolates from this study were resistant to ampicillin (100.0\%), nitrofurantion (84.6\%) and doxycycline hydrochloride $(84.0 \%)$. Similar broad resistant pattern were observed in previous studies [22, 23]. This study showed the prevalence of MDR and ESBL producing Salmonella spp. was $85.2 \%$ and $55.2 \%$, respectively. In a study conducted in South Korea found 87.2\% of Salmonella spp. were MDR isolates [13]. In Thailand, $84.4 \%$ isolates of Salmonella spp. were multidrug resistant which were isolated from chicken meat [19]. The prevalence of ESBL producing Salmonella spp. was very high compared to study performed by Wu et al. [24], which reported only 8.6\% prevalence of ESBL producing Salmonella species. Attention should be given to control the presence of high rate of ESBL-producing Salmonella in food.

Prevalence of E. coli MDR and ESBL producer strains were $80.0 \%$ and $40 \%$, respectively. Similar resistivity pattern was observed in Vietnam [14], China [25], Portugal [26], and Spain [15]. In addition, several studies have reported an increased ESBL cases from E. coli strains isolated from animals and pets $[15,26,27]$. Escherichia coli are common inhabitants of the human and animal guts and are indicators of fecal contamination in food. However, they have also emerged as important causes of nosocomial and community-acquired infections [28].

The MDR pattern of Proteus spp. showed 14 (73.7\%) isolates were multidrug resistance. Among all Proteus spp., 5 (26.3\%) isolates were ESBL producer. Numerous studies have reported presence of MDR strains Proteus species from animal sources $[29,30]$.

In overall, we found high prevalence (79.6\%) of MDR bacteria in chicken meat. It is well documented that Gram negative bacilli harbor series of antibiotic resistant genes which can be transferred to other bacteria horizontally [31]. All Gram negative bacilli isolated in this study namely E. coli, Salmonella spp. have been shown to cause different nosocomial infection [32]. This indicates that the emergence of MDR strains from chicken meat is potent threat. In this study, the prevalence of ESBL producer bacteria in chicken meat is $36.9 \%$ and ESBL producer among MDR was $34.9 \%$. ESBL production by the bacteria might be higher due to excessive use of broad spectrum antibiotics. The ESBL enzymes are mutant, plasmid-mediated beta lactamases derived from older, broad spectrum beta lactamase (e.g. TEM-1, TEM-2, SHV-1). Thus, they mediate resistance to extended spectrum (third generation) Cephalosporins (e.g., Ceftazidime, Cefotaxime, Ceftriaxone) [33].

\section{Conclusions}

This study showed high prevalence of MDR and ESBL producer Gram negative bacterial strains in chicken meat. The frequency of Gram negative bacteria as MDR and ESBL producer is elevating globally. Antibiotic resistance is a worldwide problem and its transmission from animal source to human is increasing tremendously. Both MDR and ESBL incidence are considered as extreme public health issue. The problem of the bacterial resistance to antimicrobial drugs is more troublesome to developing countries like Nepal where facilities for health care, surveillance for antibiotics medication and facilities to detect MDR and ESBL are poorly developed.

\section{Limitations}

Gram positive bacteria, yeast, and fungi were not considered in this study. We were unable to assess the quality of water used for washing purpose, and sanitation condition of the site where birds were undressed and eviscerated. Future studies should consider these factors in addressing the MDR and ESBL prevalence.

\section{Additional file}

Additional file 1. Additional tables and figures.

\section{Abbreviations}

MDR: multidrug resistance; ESBL: extended spectrum beta lactamase; SIM: sulfide, indole, motility; MRVP: methyl-red, Voges Proskauer; CLSI: Clinical and Laboratory Standards Institute; ZOI: zone of inhibition.

\section{Authors' contributions}

AS, AMB and DKC conceived the concept and design of this study. HS, RST, SK, $\mathrm{SS}$, and SN performed experimental work. AS, AMB, and DKC analyzed the data and prepared the final draft of the manuscript. All authors read and approved the final manuscript.

\section{Author details}

${ }^{1}$ Department of Microbiology, Balkumari College, Chitwan, Nepal. ${ }^{2}$ Department of Microbiology, Prithu Technical College, Institute of Agriculture and Animal Science, Tribhuvan University, Dang, Nepal.

\section{Acknowledgements}

We express sincere gratitude to all the individuals of slaughter house who provided chicken meat samples during the study. We also acknowledge to all the faculty members of Department of Microbiology, Balkumari College, Nepal.

Competing interests

The authors declare that they have no competing interests. 


\section{Availability of data and materials}

All data obtained during this study are available within the article.

\section{Consent for publication}

Not applicable.

\section{Ethical approval and consent to participate}

Ethical approval was obtained from Research Ethics Committee of Balkumari College, Tribhuvan University, Nepal. The study protocol was verified by Research Committee of Microbiology Department. No human sample was involved in this study and the animal samples were processed according to the animal research ethical guidelines. Informed written consent was obtained from all slaughterhouse owners included in the study.

\section{Funding}

No specific funding for this study was received.

\section{Publisher's Note}

Springer Nature remains neutral with regard to jurisdictional claims in published maps and institutional affiliations.

Received: 12 August 2017 Accepted: 3 November 2017 Published online: 07 November 2017

\section{References}

1. Nikaido H. Multidrug resistance in bacteria. Annu Rev Biochem. 2009:78:119-46.

2. Gelband H, Molly Miller P, Pant S, Gandra S, Levinson J, Barter D, White A, Laxminarayan R. The state of the world's antibiotics 2015. Wound Healing South Afr. 2015:8:30-4.

3. Nhung NT, Chansiripornchai N, Carrique-Mas JJ. Antimicrobial resistance in bacterial poultry pathogen: a review. Front Vet Sci. 2017;4:126.

4. Marshall BM, Levy SB. Food animals and antimicrobials: impacts on human health. Clin Microbiol Rev. 2011;24:718-33.

5. Overdevest I, Willemsen I, Rijnsburger M, Eustace A, Xu L, Hawkey P, Heck M, Savelkoul P, Vandenbroucke-Grauls C, van der Zwaluw K, Huijsdens X. Extended-spectrum $\beta$-lactamase genes of Escherichia coli in chicken meat and humans, the Netherlands. Emerg Infect Dis. 2011;17:1216-22.

6. Bhandari N, Nepali DB, Paudyal S. Assessment of bacterial load in broiler chicken meat from the retail meat shops in Chitwan, Nepal. Int J Infect Microbiol. 2013;2:99-104.

7. Rouger A, Tresse O, Zagorec M. Bacterial contaminants of poultry meat: sources, species, and dynamics. Microorganisms. 2017;5:E50. https://doi org/10.3390/microorganisms5030050.

8. Kebede A, Kemal J, Alemayehu H, Habte Mariam S. Isolation, identification, and antibiotic susceptibility testing of Salmonella from slaughtered bovines and ovines in Addis Ababa Abattoir Enterprise, Ethiopia: a crosssectional study. Int J Bacteriol. 2016;2016:3714785.

9. da Silva N, Taniwaki MH, Junqueira VCA, Silveira NFA, do Nascimento MS, Gomes RAR. Microbiological examination methods of food and water: a laboratory manual. London: Taylor \& Francis Group; 2013.

10. Clinical Laboratory Standards Institute (CLSI). Performance standards for antimicrobial susceptibility testing; 24th informational supplement (M100-S23). Wayne: CLSI; 2014.

11. Saikia P, Joshi SR. Retail market poultry meats of North-East India-a microbiological survey for pathogenic contaminants. Res J Microbiol. 2010;5:36-43.

12. Yang B, Qu D, Zhang X, Shen J, Cui S, Shi Y, Xi M, Sheng M, Zhi S, Meng J. Prevalence and characterization of Salmonella serovars in retail meats of marketplace in Shaanxi, China. Int J Food Microbiol. 2010;141:63-72.

13. Kim MS, Lim TH, Jang JH, Lee DH, Kim BY, Kwon JH, Choi SW, Noh JY, Hong YH, Lee SB, Yang SY. Prevalence and antimicrobial resistance of Salmonella species isolated from chicken meats produced by different integrated broiler operations in Korea. Poult Sci. 2012:91:2370-5.

14. Nguyen VT, Carrique-Mas JJ, Ngo TH, Ho HM, Ha TT, Campbell Jl, Nguyen TN, Hoang NN, Pham VM, Wagenaar JA, Hardon A. Prevalence and risk factors for carriage of antimicrobial-resistant Escherichia coli on household and small-scale chicken farms in the Mekong Delta of Vietnam. J Antimicrob Chemother. 2015;70:2144-52.

15. Briñas L, Moreno MA, Teshager T, Sáenz Y, Porrero MC, Domínguez $L$, Torres C. Monitoring and characterization of extended-spectrum $\beta$-lactamases in Escherichia coli strains from healthy and sick animals in Spain in 2003. Antimicrob Agents Chemother. 2005:49:1262-4.

16. Gupta N, Yadav A, Choudhary U, Aropa DR. Citrobacter bacteremia in a tertiary care hospital. Scand J Infect Dis. 2003;35:765-8.

17. Pepperell C, Kus JV, Gardam MA, Humar A, Burrows LL. Low-virulence Citrobacter species encode resistance to multiple antimicrobials. Antimicrob Agents Chemother. 2002;46:3555-60.

18. Kanamori H, Yano H, Hirakata Y, Endo S, Arai K, Ogawa M, Shimojima M, Aoyagi T, Hatta M, Yamada M, Nishimaki K. High prevalence of extended-spectrum $\beta$-lactamases and qur determinants in Citrobacter species from Japan: dissemination of CTX-M-2. J Antimicrob Chemother. 2011;66:2255-62.

19. Donado-Godoy P, Clavijo V, León M, Arevalo A, Castellanos R, Bernal J, Tafur MA, Ovalle MV, Alali WQ, Hume M, Romero-Zuñiga JJ. Counts, serovars, and antimicrobial resistance phenotypes of Salmonella on raw chicken meat at retail in Colombia. J Food Protect. 2014;77:227-35.

20. Lertworapreecha M, Sutthimusik S, Tontikapong K. Antimicrobial resistance in salmonella enterica isolated from pork, chicken, and vegetables in southern Thailand. Jundishapur J Microbiol. 2012;6:36-41.

21. Noori AL, Al Ghamdi A, Ansari MJ, Al-Attal Y, Al-Mubarak A, Salom K. Differences in composition of honey samples and their impact on the antimicrobial activities against drug multiresistant bacteria and pathogenic fungi. Arch Med Res. 2013;44:307-16.

22. Thai TH, Hirai T, Lan NT, Yamaguchi R. Antibiotic resistance profiles of Salmonella serovars isolated from retail pork and chicken meat in North Vietnam. Int J Food Microbiol. 2012;156:147-51.

23. Zhao C, Ge B, De Villena J, Sudler R, Yeh E, Zhao S, White DG, Wagner D, Meng J. Prevalence of Campylobacter spp., Escherichia coli, and Salmonella serovars in retail chicken, turkey, pork, and beef from the Greater Washington, DC, area. Appl Environ Microbiol. 2001;67:5431-6.

24. Wu H, Xia X, Cui Y, Hu Y, Xi M, Wang X, Shi X, Wang D, Meng J, Yang B. Prevalence of extended-spectrum $\beta$-lactamase-producing Salmonella on retail chicken in six provinces and two national cities in the People's Republic of China. J Food Protect. 2013;76:2040-4.

25. Tian GB, Wang HN, Zou LK, Tang JN, Zhao YW, Ye MY, Tang JY, Zhang Y, Zhang AY, Yang X, Xu CW. Detection of CTX-M-15, CTX-M-22, and SHV-2 extended-spectrum $\beta$-lactamases (ESBLs) in Escherichia coli fecal-sample isolates from pig farms in China. Foodborne Pathog Dis. 2009;6:297-304.

26. Costa D, Poeta P, Briñas L, Sáenz Y, Rodriques J, Torres C. Detection of CTX M-1 and TEM-52 $\beta$-lactamases in Escherichia coli strains from healthy pets in Portugal. J Antimicrob Chemother. 2004;54:960-1.

27. Blanc V, Mesa R, Saco M, Lavilla S, Prats G, Miró E, Navarro F, Cortés P, Llagostera M. ESBL-and plasmidic class C $\beta$-lactamase-producing $E$. coli strains isolated from poultry, pig and rabbit farms. Vet Microbiol. 2006;118:299-304.

28. Paterson DL, Bonomo RA. Extended-spectrum $\beta$-lactamases: a clinical update. Clin Microbiol Rev. 2005;18:657-86.

29. Nemati M. Antimicrobial resistance of Proteus isolates from poultry. Euro Exp Biol. 2013;3:499-500.

30. Yu W, He Z, Huang F. Multidrug-resistant Proteus mirabilis isolated from newly weaned infant Rhesus monkeys and Ferrets. Jundishapur J Microbiol. 2015:8:e16822

31. von Wintersdorff CJ, Penders J, van Niekerk JM, Mills ND, Majumder S, van Alphen LB, Savelkoul PH, Wolffs PF. Dissemination of antimicrobial resistance in microbial ecosystems through horizontal gene transfer. Front Microbiol. 2016;7:173

32. Gaynes R, Edwards JR, National Nosocomial Infections Surveillance System. Overview of nosocomial infections caused by gram-negative bacilli. Clin Infect Dis. 2005:41:848-54.

33. Shaikh S, Fatima J, Shakil S, Rizvi SM, Kamal MA. Antibiotic resistance and extended spectrum beta-lactamases: types, epidemiology and treatment. Saudi J Biol Sci. 2015;22:90-101. 